\title{
Use of Matrix-Pencil Method for Efficient Islanding Detection in Static DG and a Parallel Comparison With DWT Method
}

\author{
Sanjay Agrawal \\ Rajkiya Engineering College Ambedkar Nagar \\ Sandipan Patra \\ Technological University Dublin, sandipan.patra@tudublin.ie \\ Soumya R. Mohanty \\ Indian Institute of Technology (BHU) Varanasi
}

See next page for additional authors

Follow this and additional works at: https://arrow.tudublin.ie/engscheleart2

Part of the Electrical and Computer Engineering Commons

\section{Recommended Citation}

S. Agrawal, S. Patra, S. R. Mohanty, V. Agarwal and M. Basu, "Use of Matrix-Pencil Method for Efficient Islanding Detection in Static DG and a Parallel Comparison With DWT Method," in IEEE Transactions on Industrial Electronics, vol. 66, no. 11, pp. 8937-8946, Nov. 2019, doi: 10.1109/TIE.2018.2878125.

This Article is brought to you for free and open access by the School of Electrical and Electronic Engineering at ARROW@TU Dublin. It has been accepted for inclusion in Articles by an authorized administrator of ARROW@TU Dublin. For more information, please contact arrow.admin@tudublin.ie, aisling.coyne@tudublin.ie, gerard.connolly@tudublin.ie.

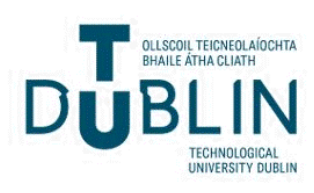




\section{Authors}

Sanjay Agrawal, Sandipan Patra, Soumya R. Mohanty, Vineeta Agarwal, and Malabika Basu

This article is available at ARROW@TU Dublin: https://arrow.tudublin.ie/engscheleart2/266 


\title{
Use of Matrix-Pencil Method for Efficient Islanding Detection in Static DG and a Parallel Comparison With DWT Method
}

\author{
Sanjay Agrawal ${ }^{\circledR}$, Sandipan Patra ${ }^{\circledR}$, Student Member, IEEE, \\ Soumya R. Mohanty ${ }^{\circledR}$, Senior Member, IEEE, Vineeta Agarwal ${ }^{\circledR}$, Senior Member, IEEE, \\ and Malabika Basu (1), Member, IEEE
}

\begin{abstract}
Islanding or nonislanding events in gridconnected distributed generation bring along a typical distinguishable transient signature in its frequency profile. This demarcation leads to the development of a new islanding protection approach, which is based on the estimation of frequency waveform parameter (transient's frequency) by Matrix pencil (MP) method. To demonstrate the efficacy of the proposed MP method, four critical scenarios are considered in this paper for covering all possible disturbance events. These events are also compared along with a discrete wavelet transform (DWT) based islanding detection method in simulations as well as in RT-LAB-based real-time environment. It is noteworthy to mention that the proposed MP method has been found to have a positive edge over the DWT-based method in terms of robustness and chances of misidentification.
\end{abstract}

Index Terms-Discrete wavelet transform (DWT), distributed generation, islanding, Matrix pencil (MP), transient's frequency.

\section{INTRODUCTION}

I SLANDING occurs when a part of the system is disconnected from the grid and remains energized by the distributed generator (DG) [1], [2]. According to the IEEE Std. 1547 [2], the unintentional island should be exposed and isolated within two seconds for small voltage and frequency signal variation. Generally, frequency and voltage of point of common coupling (PCC)

Manuscript received May 17, 2018; revised August 14, 2018 and September 18, 2018; accepted October 5, 2018. Date of publication October 31, 2018; date of current version June 28, 2019. This work was supported by the Science Foundation Ireland-International Strategic Cooperation Award Programme (SFI-ISCA). The real time implementation is performed in Dublin Institute of Technology, Ireland. (Corresponding author: Malabika Basu.)

S. Agrawal is with the Department of Electrical Engineering, Rajkiya Engineering College Ambedkar Nagar, Ambedkar Nagar 224122, India (e-mail: sanjay.ucer2009@gmail.com).

S. Patra and M. Basu are with the School of Electrical and Electronic Engineering, Dublin Institute of Technology, D08 NF82 Dublin, Ireland (e-mail: sandipan.patra@dit.ie; mbasu@dit.ie).

S. R. Mohanty is with the Department of Electrical Engineering, Indian Institute of Technology (BHU), Varanasi 221005, India (e-mail: soumyaigit@gmail.com).

V. Agarwal is with the Department of Electrical Engineering, MNNIT, Allahabad 211004, India (e-mail: vineeta@mnnit.ac.in).

Color versions of one or more of the figures in this paper are available online at http://ieeexplore.ieee.org.

Digital Object Identifier 10.1109/TIE.2018.2878125 waveform cross the prespecified limit when power mismatch is large and can be easily detected by under/over frequency and voltage relay within the specified period. Islanding detection becomes difficult when power mismatch is small, and frequency and voltage of PCC remain within a specified limit. Several islanding detection techniques have been proposed in the literature. These methods are broadly classified into two categories: Centralized (remote) method and local method [3].

Centralized method is very efficient in island detection, but its implementation cost is very high and requires regular updates about the change in the system configuration. Thus, for smallscale distributed generation local (active and passive) method is more preferred than the central method. Both active and passive methods have their own advantages and disadvantages. The efficacy of islanding detection scheme is measured regarding the smaller nondetection zone (NDZ) and faster time of detection. NDZ in $P-Q$ plane indicates the range of active and reactive power mismatch between DG and local load for which islanding remains undetected [4].

Active methods [5]-[8] have relatively smaller NDZ as compared to passive techniques; but it has some limitations like the deterioration of power quality during the normal power system operation and can also result in the false detection when injected external disturbance is nullified in the multi-DG system [9]-[13]. Passive islanding detection techniques, on the other hand, do not have any negative impact on grid power quality, but depends on the measurement of local system parameters at the PCC. It is often not easy to determine the significant parameter and its threshold value to detect islanding event because many other nonislanding disturbances have transients that resemble very closely to an islanding event. Thus, thresholds on the measured parameters (for example, frequency or voltage) are set sufficiently large enough to avoid maloperation, which in turn results in the formation of significant NDZ. Under voltage/over voltage, under/over frequency [14], [15], the rate of change of frequency [16], phase jump detection [17], the rate of change of phase angle difference [18], and voltage harmonic detection [19], [20] are the most popular passive islanding techniques. These methods exhibit large NDZ. To reduce the NDZ, power system researchers devised signal processing based on passive islanding techniques [21]. It extracts a hidden characteristic of 
the measured signal, which plays an important role in islanding detection. Fourier transform, DWT [21]-[26], S-transform [27], empirical mode decomposition [28], time-time transform [29], total least square estimation of the signal parameter by rotational invariance techniques [30], Tufts-Kumaresan signal estimation method [31], and frequency oscillation estimation based islanding detection [32] are several useful signal processing tools applied for the islanding detection. Out of these signal-processing algorithms, discrete wavelet transform (DWT) is a strong candidate for the implementation of the islanding detection scheme [26], [33]-[36]. In this paper, a proposed Matrix pencil (MP) method based signal processing technique is compared with the standard DWT signal processing technique.

The proposed technique is based on the estimation of the transient frequency of the disturbed frequency waveform at the PCC. The disturbance effect on frequency waveform for nonislanding event and islanding event are different. This demarcation happens due to the fact that synchronizing power becomes zero in case of islanding event. The MP method is used for estimation of this transient's frequency because it works directly on the input data matrix and calculates the poles in a single process by solving generalized eigen value equations. These features make it computationally efficient for the estimation of frequency. Although the computational burden is a bit higher than that of DWT-based islanding, the efficacy of the proposed scheme is superior when the grid is polluted with higher-order harmonics. As a matter of fact, the accuracy and elegance of the proposed MP method can make a compromise with slight more computational time, keeping in mind the criteria of IEEE 1547 in order to detect the islanding phenomena within two seconds. The following Sections II, III, and IV discuss the theory and application of these two techniques, and performances are compared in Sections V and VI where four different critical scenarios are considered to evaluate the algorithm more critically for NDZ, quality factor (QF) of the load, effect of nonlinear load current harmonics, detection time, and possible failure or misidentification.

\section{Proposed MP Method and its Application}

MP method is a class of mathematical approach to estimate signal parameters of a signal consisting of multiple damped sinusoids. In the context of identification of islanding events, the estimation of real-time frequency components is of interest, and a formulation of MP approach is presented in the following.

In general, the waveform to be analyzed from an islanding event can be expressed as

$y(n)=\sum_{k=1}^{M} a_{k} e^{\left(-d_{k}+j 2 \pi f_{k}\right) n T_{s}}+\eta(n) \quad \mathrm{n}=0,1, \ldots, \mathrm{N}-1$

where $a_{k}, f_{k}$, and $d_{k}$ are the complex amplitude, transient frequency, and damping factor of the kth sinusoidal component; $\mathrm{M}$ represents the number of the sinusoids present in the signal, $\eta$ accounts for the noise in the signal (assumed to be white), $\mathrm{N}$ is the total number of samples, and $T_{s}$ is sampling time.
The estimation of transient frequencies $f_{k}$ related to the estimation of the poles $-d_{k}+j 2 \pi f_{k}$ of the signal, can be obtained by different approaches and is a nontrivial matter. MP method is followed to estimate $f_{k}$ as outlined briefly by the following derivation.

MP method uses certain properties of the underlying signal. Let us define.

Data matrix of order $(N-L) \mathrm{x}(L+1)$ is directly obtained from the data sequence $y(n)$ as

$$
Y=\left(\begin{array}{cccc}
y(0) & y(1) & \ldots & y(L) \\
y(1) & y(2) & \ldots & y(L+1) \\
\vdots & \vdots & \ddots & \vdots \\
y(N-L-1) & y(N) & \cdots & y(N-1)
\end{array}\right)
$$

where, $L$ is called the pencil parameter. Some results from [37] and [38] are used for transient frequency estimation in this paper. To use some results from Theorem 2.1 in [37] two new matrices are formed. These two matrices $Y_{1}$ and $Y_{2}$ are derived from $Y$ by deleting its last and first row, respectively.

According to Cramer-Rao bound, $L$ is chosen between N/3 and $2 N / 3$ for the optimum estimator and efficient data filtering [38]-[41].

In this paper, prior to applying the MP approach, singular value decomposition (SVD) is proposed to be performed on the matrix $Y$ for denoising

$$
Y=U \sum V^{H} \text { and } U^{H} Y V=\sum .
$$

Here, $(.)^{H}$ is a hermitian operator, $U=Y Y^{H}$ and $V=Y^{H} Y$ are the unitary matrices, and main diagonal elements of $\sum$ represent the individual singular value $\sigma_{i}$ of the matrix $Y$. These eigenvalues are arranged in descending order $\sigma_{1} \geq \sigma_{2} \geq \cdots \geq$ $\sigma_{i} \geq \cdots \geq \sigma_{\min }$. If the data is free from noise, $M=\max (i)$ for which $\sigma_{i}>0$.

If noise is also present in the signal, the singular values smaller than a certain value $(\alpha)$ are considered as noise and are filtered out by choosing a signal component number $(M)$ such that $M=$ $\max (i)$ for which $\frac{\sigma_{i}}{\sigma_{\max }}>\alpha$.

The value of $\alpha$ is chosen depending on the application. In this paper, since high-frequency noises are to be eliminated, a low value (e.g., 10-3) is to be chosen.

After getting the value of $M, M$-dominant singular value vector of matrix $V$ is selected to form new signal matrices $V_{s}$ and the rest $M+1$ to $L$ are discarded.

$\sum_{s}$ is obtained from the $M$ columns of $\sum$ corresponding to the $M$-dominant singular values, $Y_{1}$ and $Y_{2}$ for signal part only become

$$
\begin{aligned}
& Y_{1}=U_{s} \sum_{s} V_{1 s}^{H} \\
& Y_{2}=U_{s} \sum_{s} V_{2 s}^{H} .
\end{aligned}
$$

Here, matrices $V_{1 s}$ and $V_{2 s}$ are formed from $V_{s}$ by deleting its last and first rows, respectively. The diagonal matrix $\sum_{s}$ is formed from $M$-dominant values of $\sum$ after doing SVD. 


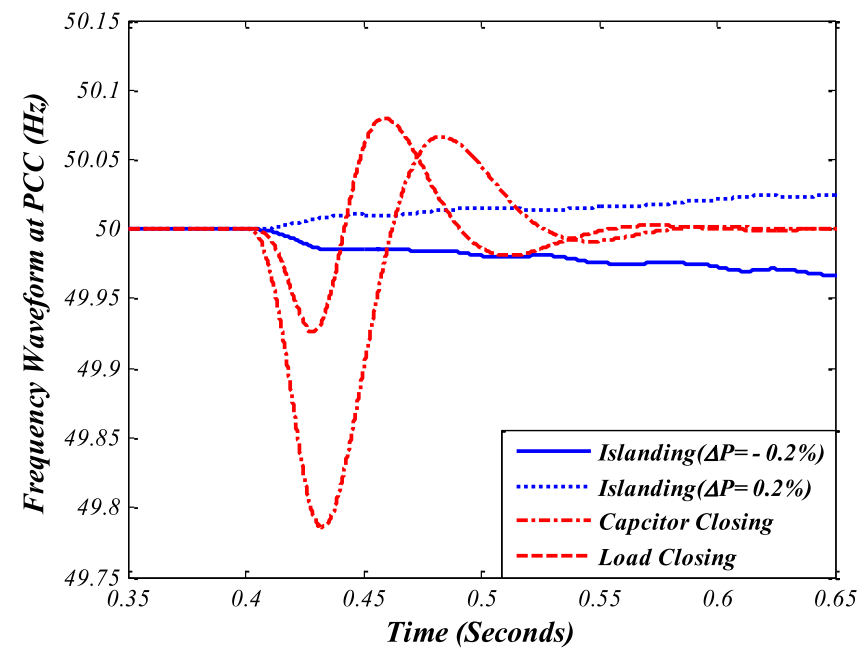

Fig. 1. Behaviour of frequency at PCC.

Eigen values $\lambda_{k}$ are the signal poles and can be found by using the concept of Moore-Penrose or pseudoinverse as follows:

$$
\left(Y_{1}^{H} Y_{1}\right)^{-1} Y_{2}=\lambda I_{M \times M} \text {. }
$$

Frequency $f_{k}$ and damping coefficients $d_{k}$ of the signal components are estimated by using (10) and (11), respectively

$$
\begin{aligned}
f_{k} & =\frac{\angle \lambda_{k}}{2 \pi} \\
d_{k} & =\operatorname{Re}\left(\log \left(\lambda_{k}\right)\right) .
\end{aligned}
$$

Any kind of disturbances manifest transients in the system and the nature of these transients depend upon the type of disturbances. Frequency pattern at PCC is different for islanding and nonislanding events. The frequency waveform at PCC is shown in Fig. 1. For islanding events, the disturbance transients in the frequency waveform is growing or decaying for positive and negative power mismatch, respectively [31], [37] whereas for nonislanding events, the disturbance transient is damped sinusoid. For nonislanding events, there is participation from the grid toward damping these oscillations by sharing of active and/or reactive power appropriately. In this paper, this unique feature has been utilized to develop a new anti-islanding protection scheme based on the estimation of disturbance "transient's frequency."

As power mismatch increases, steepness of the frequency deviation curve also increases and this results in less number of cycles/ revolution within the particular time. Thus, the disturbance "transient's frequency" for islanding event increases as power mismatch decreases, and it reaches up to its maximum value (Th2) when power mismatch is zero, and it will depend on the system configuration.

This disturbance "transient's frequency" for the nonislanding event (load switching, capacitor bank switching, distribution line faults, etc.) is much higher than Th2. The threshold value (Th2) of disturbance transient's frequency is determined by performing a series of simulations with different possible case study scenario. Thus, it has been determined that islanding event occurs when the disturbance "transient's frequency" lies between zero to Th2.

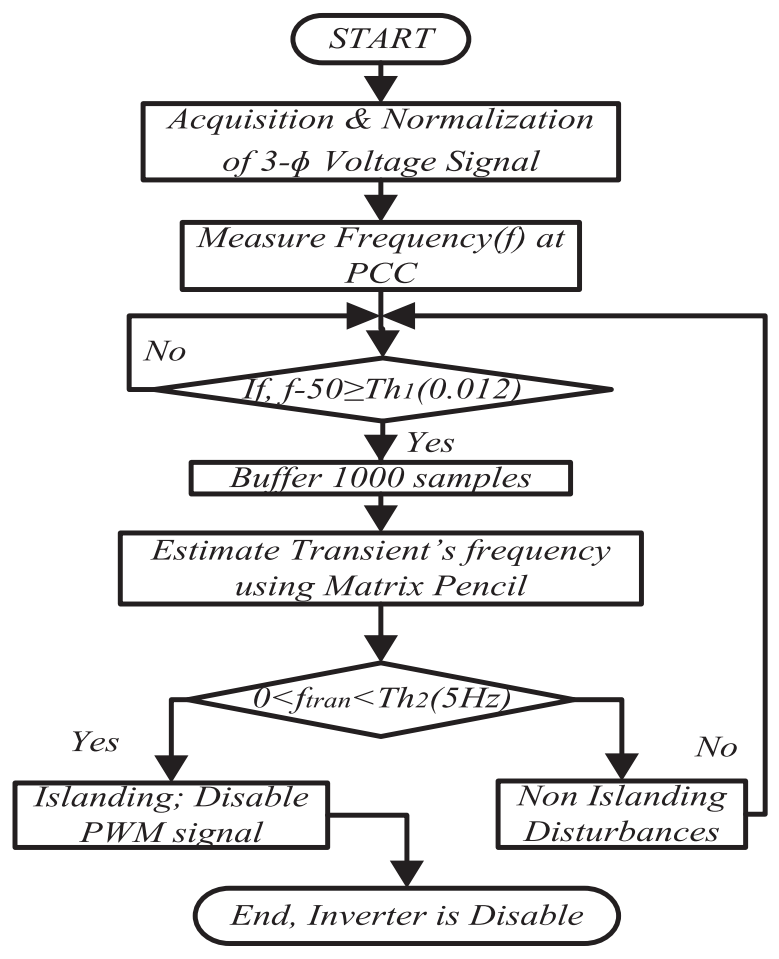

Fig. 2. Flow chart of proposed islanding detection with MP method.

A flowchart of the proposed algorithm is shown in Fig. 2. In this case, the frequency of the PCC voltage signal is measured using phase-locked loop (PLL) and sampled with a sampling rate of $10 \mathrm{kHz}$. Then the difference between the measured and nominal frequency $(50 \mathrm{~Hz})$ is compared with a threshold (Th1) to discriminate whether the system is in normal operating condition or not. If the difference between the measured and nominal frequency crosses the threshold limit (Th1); it means the system is subjected to noticeable disturbance, and subsequently, it initiates data buffering. When buffered data samples are equal to 1000 samples, it goes to the transient frequency estimation block. In the transient frequency estimation block, MP function is embedded into MATLAB Simulink to estimate the transient frequency. Estimated transient frequency is compared with a threshold (Th2) in order to discriminate the islanding and nonislanding events. When estimated transient frequency lies between zero and Th2 (indicative of islanding event), the islanding detection block disables the PWM signals to stop further DG generation. If transient frequency lies outside the upper and Th2 (indicating nonislanding event); PWM signal remains enabled and DG generation continues until further detection of disturbances. The algorithm continues to check the frequency difference to distinguish between islanding and nonislanding events.

\section{DWT-Based IsLanding Detection Method}

DWT has the ability to analyze signals in both time and frequency domains, simultaneously. DWT decomposes the signal into different frequency bands. This helps in reducing the computational burden, extracting the features and eliminating the noise. The energy of the DWT coefficients depends upon the 


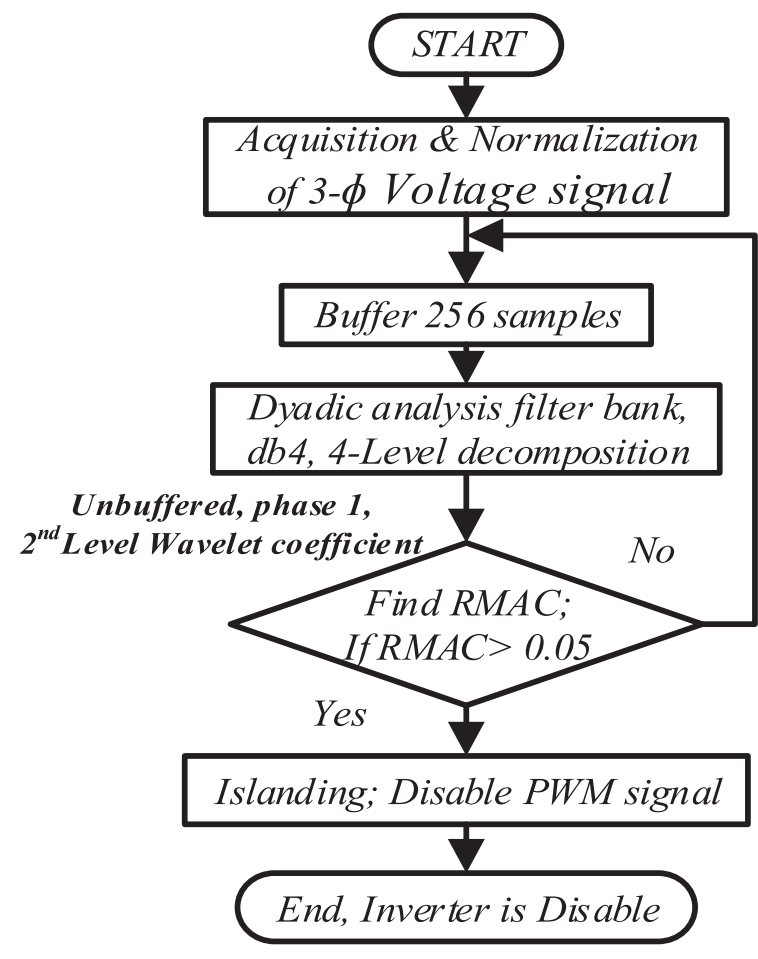

Fig. 3. Flow chart of DWT-based islanding detection method.

number of frequency components and their strength that lies within the frequency band of DWT coefficients. DWT-based islanding detection employs the concept of change in frequency components from grid connected to islanded mode. According to that change, it sets up thresholds to detect islanding events. This feature makes it powerful in the detection of islanding events, but it can also mal-operate when frequency change for other disturbance is analogous to islanding events.

Authors in [26], [33]-[36] presented a DWT-based passive island detection technique. In this paper, PCC voltage signal is acquired with sampling frequency of $5 \mathrm{kHz}$. Daubechies 4 (DB4) is used as mother wavelet to evaluate DWT coefficients of the PCC voltage signal. PCC voltage signal is decomposed up to four levels $d 1(1250-2500 \mathrm{~Hz}), d 2(625-1250 \mathrm{~Hz}), d 3$ $(312.5-625 \mathrm{~Hz})$, and $d 4(156.25-312.5 \mathrm{~Hz})$ using the multiresolution analysis.

The characteristic of different DWT coefficient for normal and islanding condition are analyzed when the grid is free from harmonics. It is found that the difference in energy of $d 2$ level coefficient for grid-connected and the islanded mode is maximum as compared to other levels. Thus, the $d 2$ level is selected for islanding and nonislanding discrimination. Discrimination based on a change in the magnitude of the wavelet coefficient may lead to nuisance tripping to other transients (load change, capacitor switching, etc.). Thus, to avoid such situation, root mean absolute of second level wavelet coefficient (RMAC) [26] is used to develop DWT-based islanding algorithm, and its flow chart is shown in Fig 3.

\section{SYSTEM UNDER INVESTIGATION}

To test the effectiveness of the proposed algorithm, the system is shown in Fig. 4(a). The control topology adopted to generate

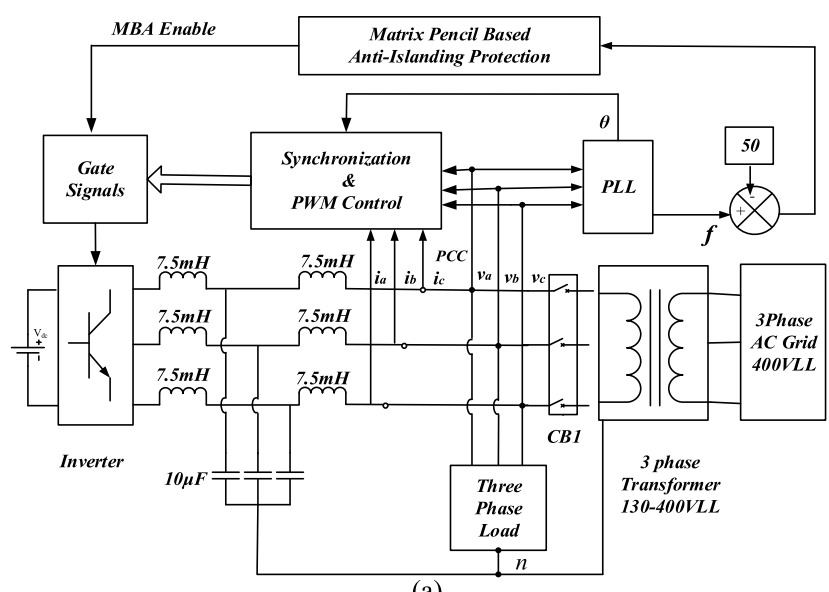

(a)

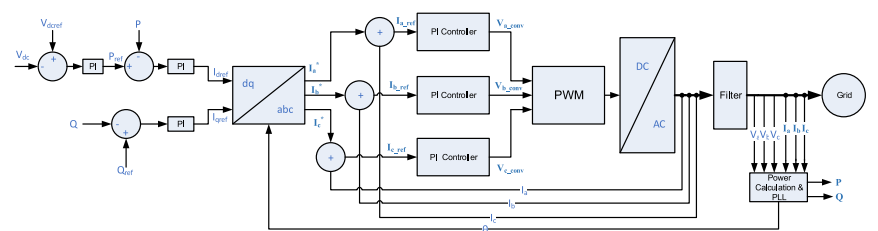

(b)

Fig. 4. (a) Block diagram of system setup. (b) Control scheme for PWM generation.

the PWM signal is shown in Fig. 4(b). MATLAB /Simulink platform is used to simulate the system. Further, the same system has been realized in OPAL-RT platform to demonstrate the effectiveness of the proposed algorithm in real-time environment. The system consists of an inverter-based DG, a three-phase RLC load, transformer, and the grid. The DG unit contains a three-phase PWM inverter, dc voltage source of $400 \mathrm{~V}$, and LCL filter. The islanding is created with the opening of the grid circuit breaker (CB1).

In this system, the voltage signal is sensed at the PCC. RMS and peak value of the voltage signal is continuously calculated to normalize it to $1-\mathrm{V}$ peak-peak such that any distortion can be reflected in this normalized signal. PLL is used to measure the frequency and phase of normalized voltage. Synchronization and PWM control estimates required peak inverter voltage $\left(V_{\text {inv peak }}\right)$ and load angle $(\delta)$ using standard power flow theory and generate a sinusoidal reference signal for PWM pulse generation to control the inverter output. Table I in the Appendix gives the full system parameters for this study.

\section{Simulated Results With Discussion}

In this section, DWT and proposed MP method performance are tested based on simulation results under various scenarios. Table II in the appendix gives a summary of the power mismatch considered and the estimated transient's frequency. Individual cases are elaborated here. Due to page limitation, only critical case studies have been shown in the manuscript as both the techniques are efficiently detecting islanding in extreme case studies like close to zero power mismatch (DG source generation and load demand is almost same) and large power mismatch. However, the most crucial real-time result of close to zero power mismatch is presented in the subsequent section. 

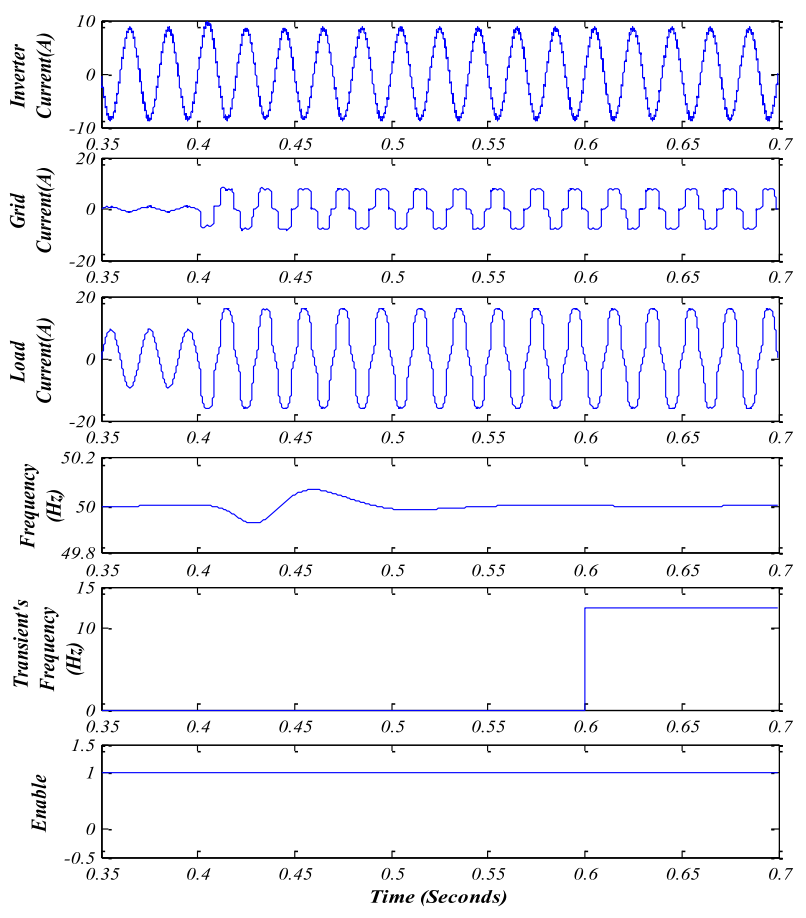

(a)
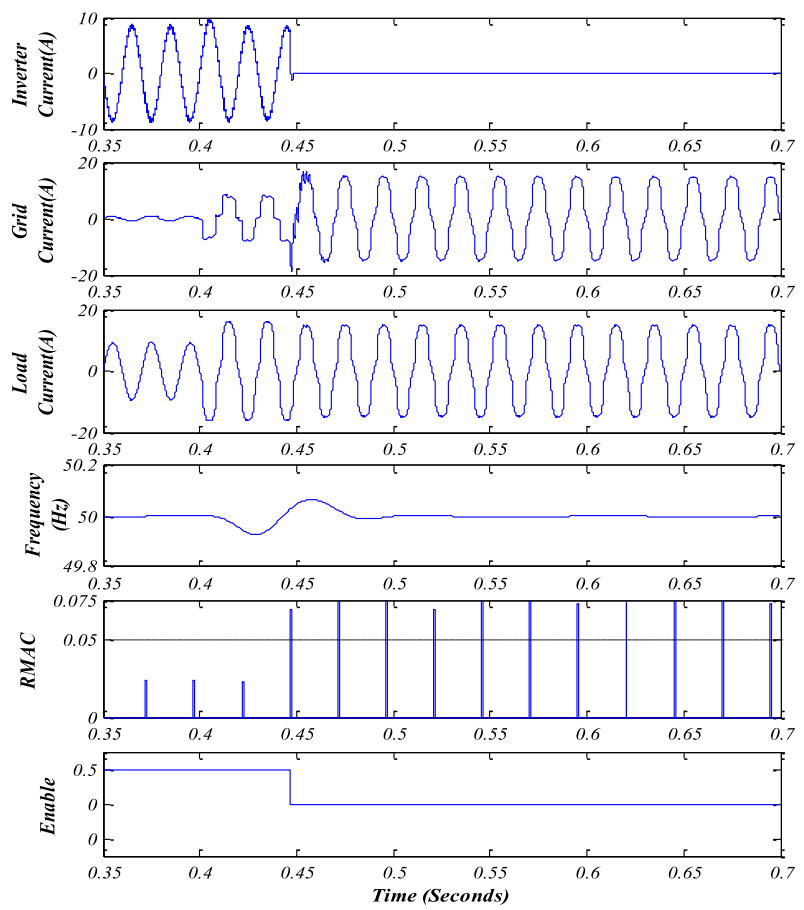

(b)

Fig. 5. Simulation result of nonlinear load switching with (a) proposed MP method and (b) DWT method.

\section{A. Nonlinear Load Switching}

In this section, the reliability of the proposed MP method and DWT-based islanding detection method is tested when a nonlinear load is added at the instant $0.4 \mathrm{~s}$. MP method and DWT in the context of comparative performance are shown in Fig. 5(a) and (b), respectively. From the results, it is clear that the proposed MP technique outperforms and accurately detects it as a nonislanding event even if the switched load is nonlinear in nature. Whereas, in the case of the DWT method, RMAC value crosses the threshold level, which leads to mal-operation as shown in Fig. 5(b). To avoid mal-operation, the threshold value of RMAC must be set at a higher level. It is undesirable to increase the threshold level because it will result in larger NDZ.

\section{B. Capacitor Switching}

In this case, before the capacitive load switching, DG feeds power to 1.4-kW local load; thus power exchange from the grid is almost negligible (grid current is zero). In the event of capacitive load switching, power has been drawn from the grid (grid current value increases from zero) to meet the additional power requirement of the capacitive load. To study the efficacy of islanding detection algorithm under such scenario, a 450 VAR of capacitive load is added at the instance $0.4 \mathrm{~s}$, which results in a switching type nonislanding event. Result in Fig. 6(a) shows that the frequency of PCC voltage signal starts oscillating from the instant $0.4 \mathrm{~s}$ and estimated transient frequency is greater than the Th2. Thus, DG supply remains enabled.

In the case of the DWT-based method, RMAC value increases from the preset threshold value of 0.05, as shown in Fig. 6(b), recognizes it as islanding event and disables the DG power supply. This is a practical case example where the proposed MP method is more reliable than that of the DWT method for proper discrimination between islanding and nonislanding events. It is noteworthy to mention that 450 VAR capacitive load acts as a threshold, below which the wavelet-based relay, operate perfectly, but exhibits mal-operation for 450 VAR and above capacitive load switching. This situation occurs because the energy of the wavelet coefficients are found to be too low to reach the threshold 0.05 for cases lower than 450 VAR capacitive load switching. Proposed MP method has also been tested for different ratings higher and lower than the $450 \mathrm{VAR}$, but does not show any malfunction.

\section{Effect of Grid-Voltage Harmonics on Islanding Detection}

To demonstrate the effect of grid harmonics effect on the performance of the proposed MP and DWT-based technique, an analysis has been presented in this section (see Fig. 7). Grid harmonics can also sometime affect DWT-based technique performance. This is due to the fact that DWT decomposes the signal in frequency bands as mentioned in section III. In the present study, the $d 2$ level band is used for the islanding detection. Variation in harmonic component that lies within this frequency band may lead to malfunctioning of DWT-based island detection algorithm. Thus, to check the performance of DWT and proposed MP method, harmonics of order 13 and 17 are added to grid voltage at the instance $0.4 \mathrm{~s}$. The magnitude of added harmonics is quite small. It is equal to $0.58 \%$ and $0.68 \%$ of the fundamental for harmonics order 13 and 17 , respectively, which is much lower than the permissible limit of IEEE Std. 519.

It is found from Fig. 7(b) that RMAC values crosses the set threshold and interpret it as islanding event. This situation occurs because the energy of $d 2$ level is increased due to the addition of 

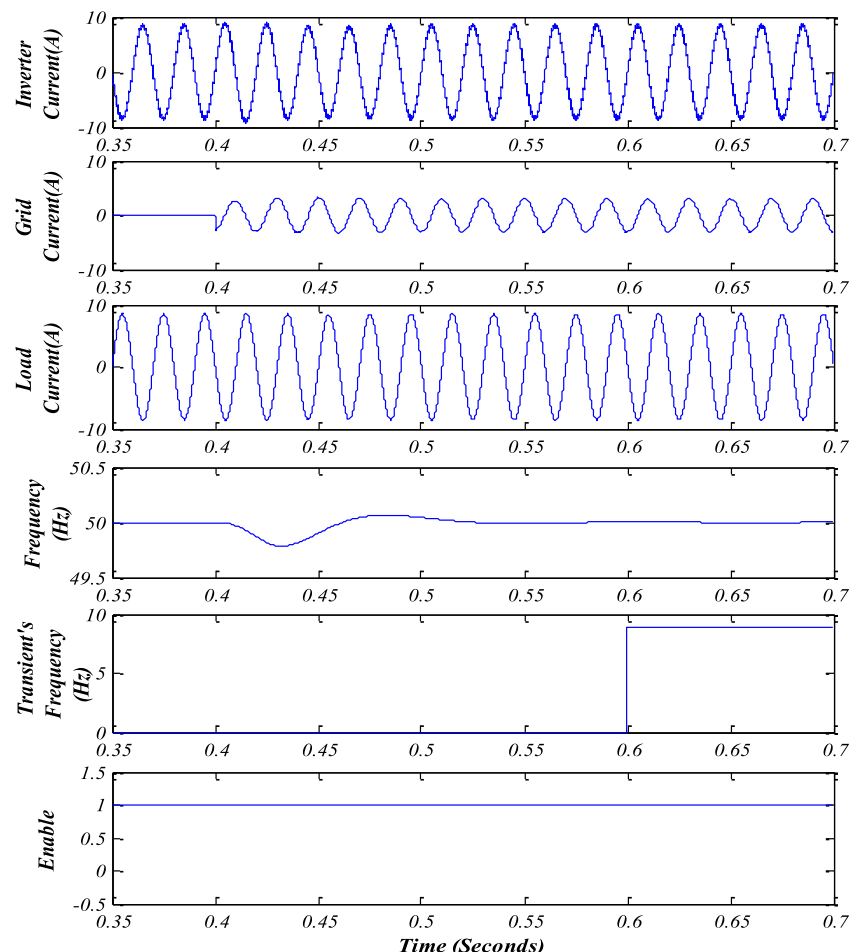

(a)
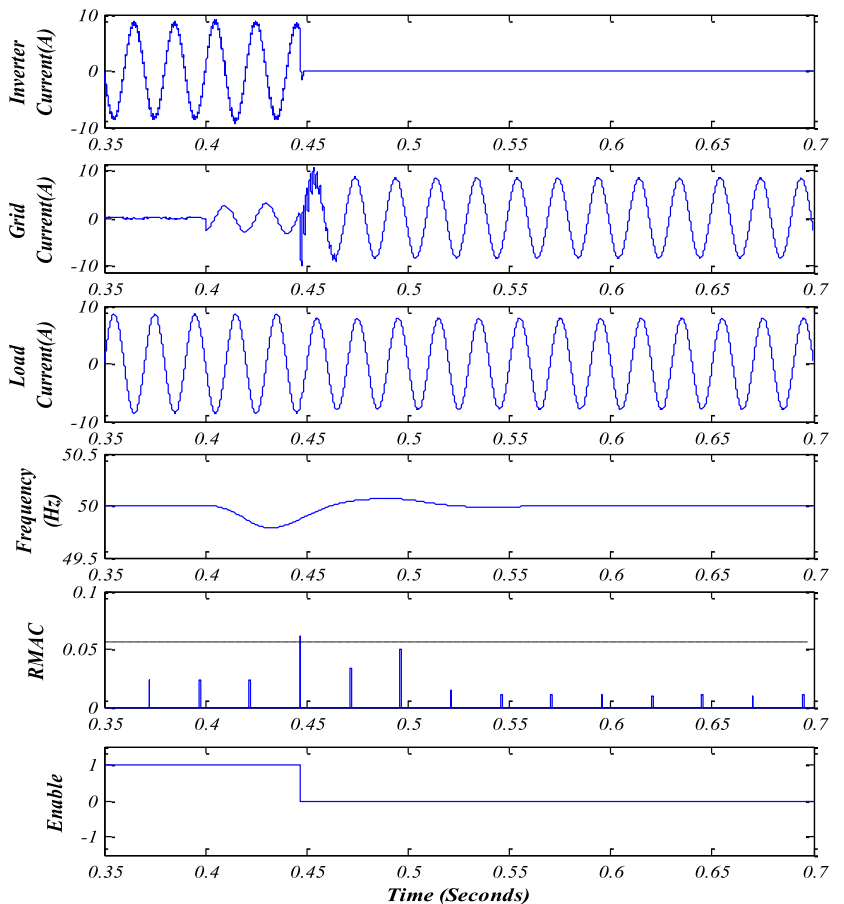

(b)

Fig. 6. Capacitor switching (nonislanding event) with (a) proposed MP method and (b) DWT method.

harmonics of order 13 and 17. To avoid the malfunction of DWTbased islanding detection technique, it needs a measurement of grid voltage harmonics, and the threshold has to be appropriately adjusted. It also introduces a remarkable delay for the regular update of thresholds, which is not a feasible solution. Proposed MP technique performance is not affected by the harmonics variation. The simulation results are shown in Fig. 7(a) and (b)
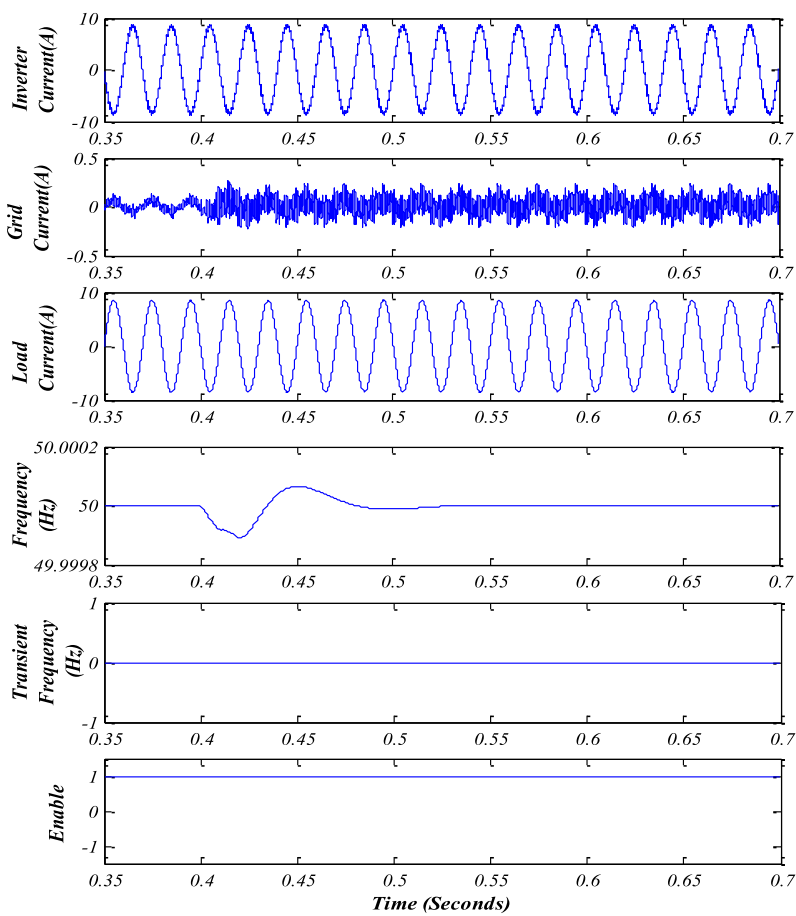

(a)
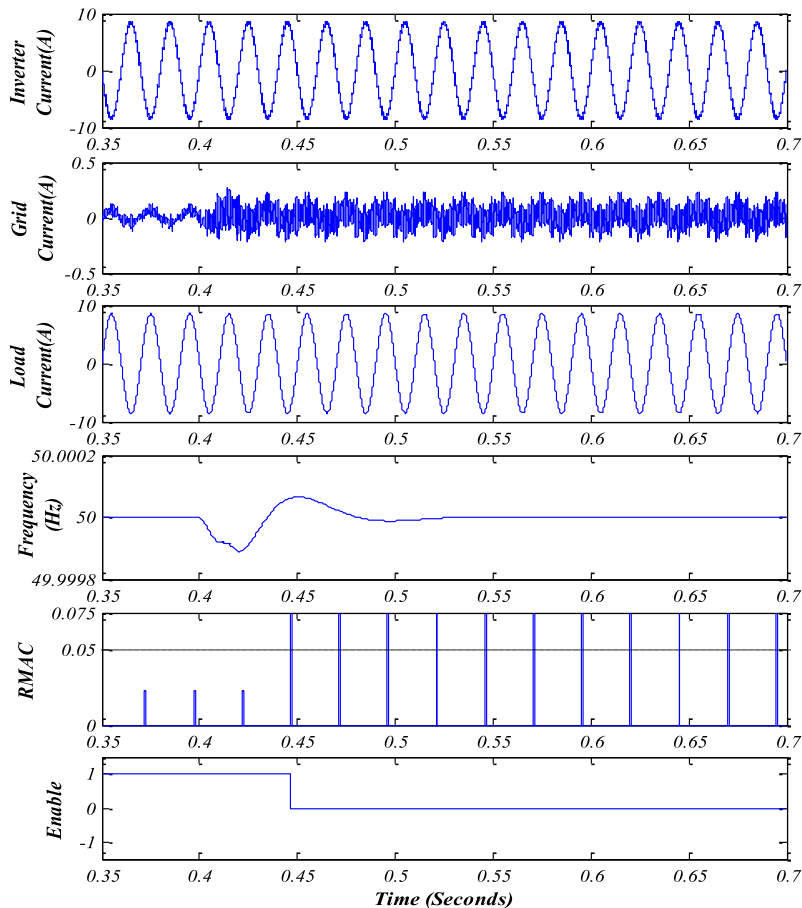

(b)

Fig. 7. Effect of 13 and 17 order harmonics on (a) proposed MP method and (b) DWT method.

that confirm the superiority of the proposed MP technique over DWT in the presence of grid harmonics.

\section{Effect of Load QF on Islanding Detection}

Load QF also affects the islanding detection. Islanding detection becomes difficult for the RLC load having QF greater than the 2.5 [26]. Proposed MP and DWT based islanding detection 


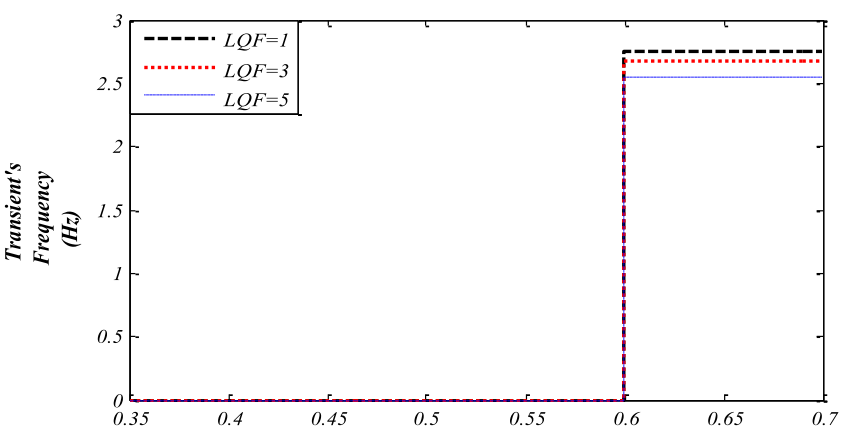

(a)

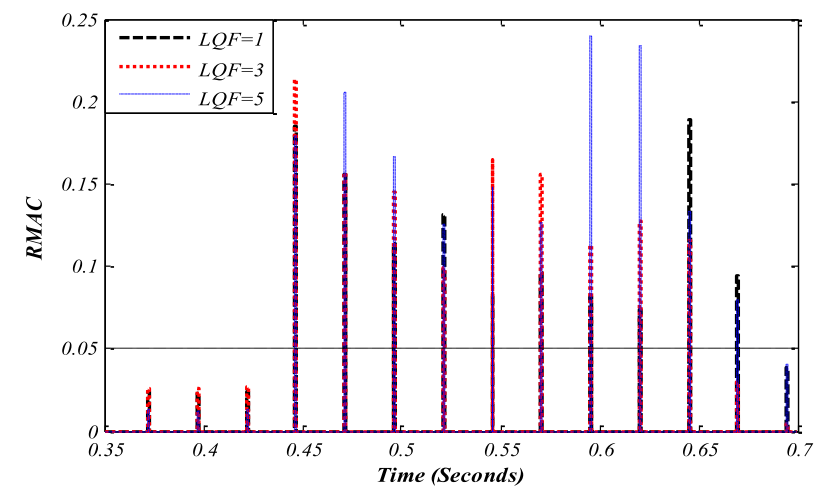

(b)

Fig. 8. Effect of load quality on (a) proposed MP method and (b) DWT method.

method are tested for three different values of load QF. It can be seen from Fig. 8 that for all the three cases, the proposed MP method and DWT method exhibit accurate islanding detection. It is clear, from Fig. 8(b), that as the load QF increases, the estimated transient's frequency by MP method decreases. Thus, load QF does not affect the islanding detection property of the proposed MP method. DWT method also detects the islanding condition correctly as shown in Fig. 8(b).

\section{Real-Time Results With Discussion}

The proposed system is implemented in RT-LAB simulator (OP5600), which uses field programmable gate array (FPGA) architecture with Xilinx system generator toolbox to realize the virtual prototype of the system as shown in Fig. 9. The virtual prototype of the system, which is in "software in the loop (SIL)" is almost similar to the "hardware in the loop (HIL)" as it is implemented with the proper delay management of actual signals and control signals through actual analog-digital/digitalanalog (AD/DA) devices. The communication between CPUs (PC \& OPAL-RT) is controlled by the FPGA architecture and the console PC. All the real-time results obtained from OPALRT are scaled down by 10 in magnitude.

In this section, real-time validation of proposed MP method and its comparison with wavelet transform is presented for the critical cases, such as zero power mismatch (see Fig. 10). Effect of nonlinear load variation and presence of grid harmonics are presented in the Figs. 11 and 12, respectively.

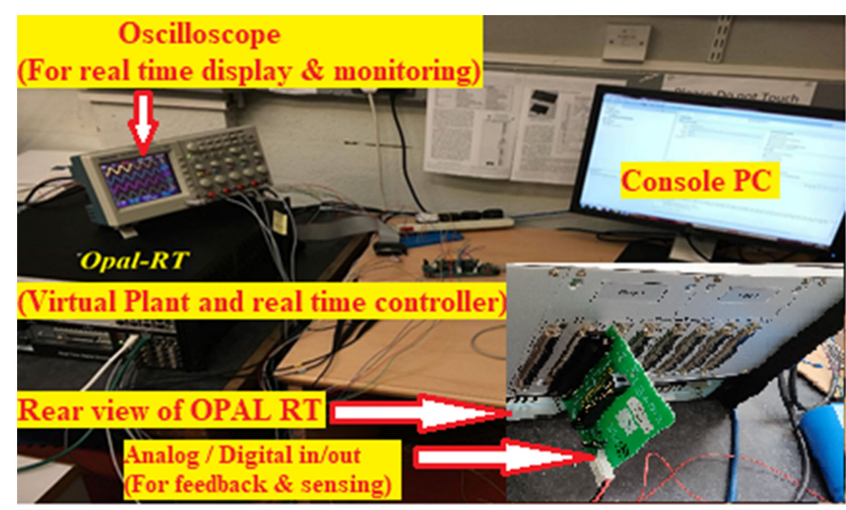

Fig. 9. Opal-RT laboratory setup.

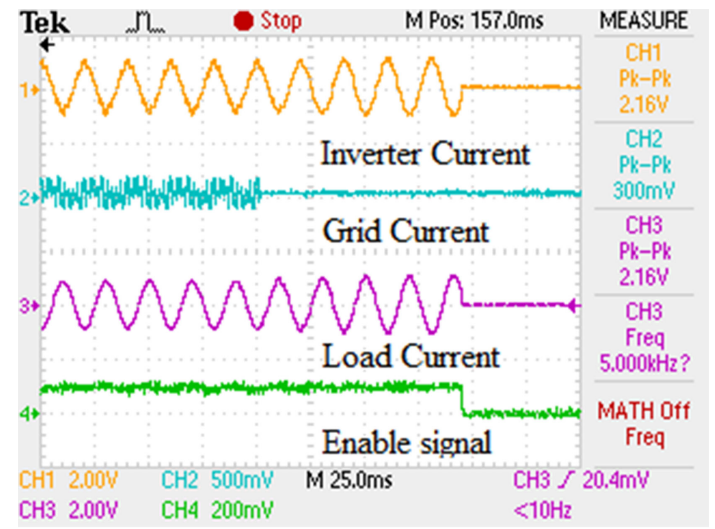

(a)

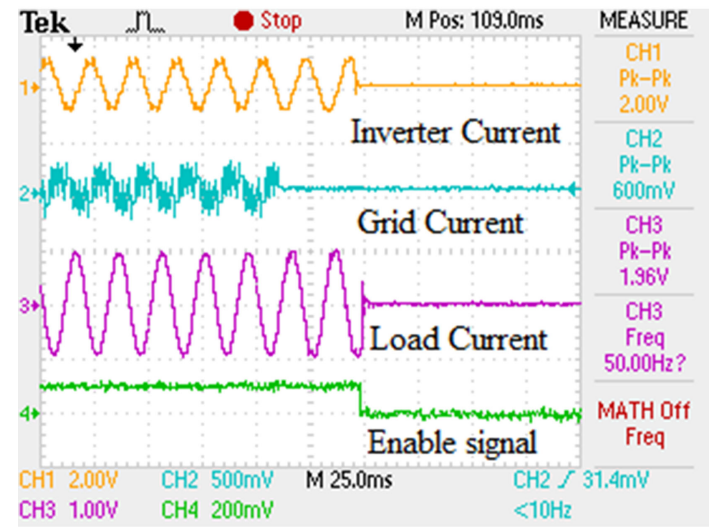

(b)

Fig. 10. Real-time result of close to zero power mismatch with (a) proposed MP method and (b) DWT method.

It has been observed from the Fig. 10(a) that islanding detection time of proposed MP method is reduced to $0.1 \mathrm{~s}$ in comparison to the detection time of $0.2 \mathrm{~s}$ in a simulated environment. It means the computational burden of the proposed method is not very significant in the OPAL-RT environment. Thus, it is well suited for the real-time islanding detection. Wavelet-based method detection time $(0.03 \mathrm{~s})$ in real time was also reduced as compared to the detection time $(0.07 \mathrm{~s})$ in a simulated case. From the result shown in Fig. 10, it is clear that both the methods are capable of detecting islanding accurately. 


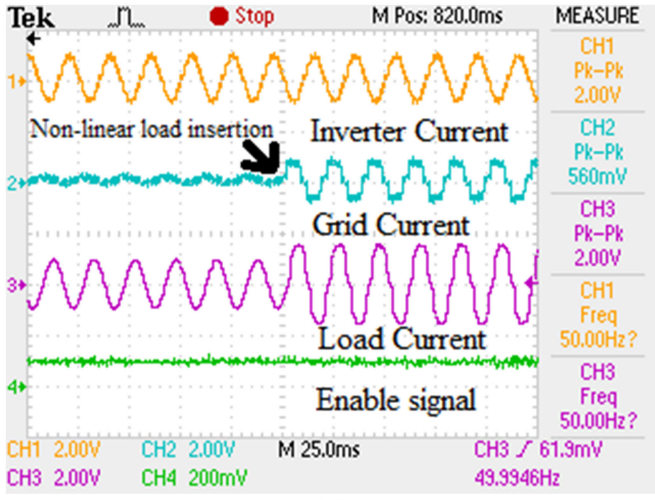

(a)

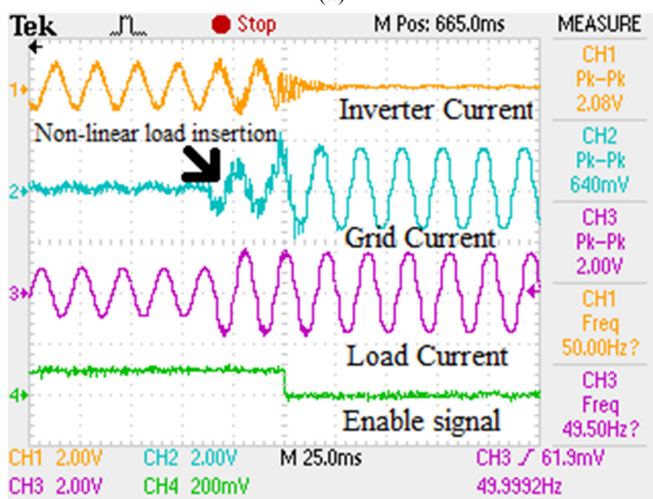

(b)

Fig. 11. Real-time result of the effect of nonlinear load (nonislanding event) with (a) proposed MP method and (b) DWT method.

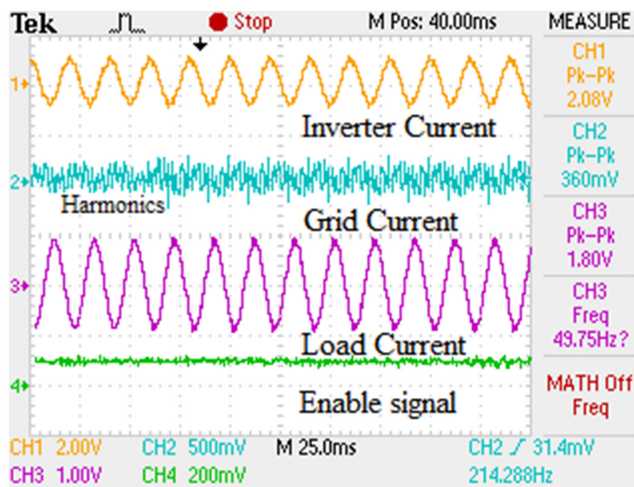

(a)

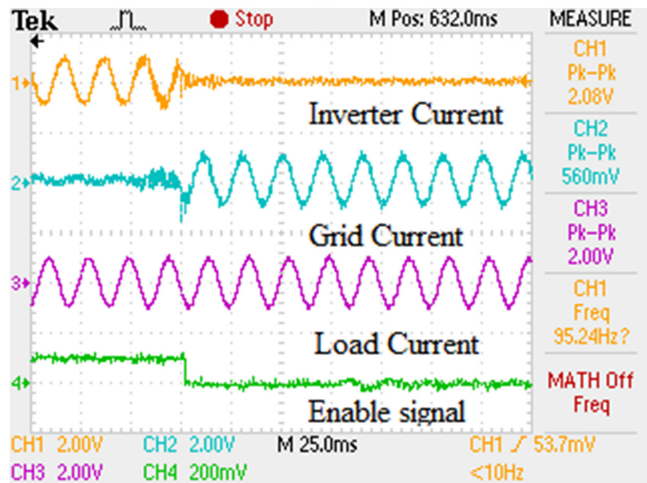

(b)

Fig. 12. Real-time result of effect of 13 and 17 order harmonics on (a) proposed MP method and (b) DWT method.
From the results shown in Fig. 11(a) (similar to case study in section V-A nonlinear load switching) and Fig. 12(a) (similar to case study in section $\mathrm{V}-\mathrm{C}$ presence of voltage harmonics in grid), it is clear that in real time environment, proposed MP method can clearly discriminate these events as nonislanding disturbances and continues the DG supply. Whereas, DWT method malfunctions in these events as are shown in Figs. 11(b) and 12(b) and stops the DG supply.

\section{CONCLUSION}

In this paper, disturbance transient's frequency estimation was treated as the dominant criteria to discriminate islanding and nonislanding events. In the case of islanding events, frequency variation will monotonically increase or decrease. On the other hand, in the case of nonislanding events, the frequency will be oscillating in nature. This basic difference is exploited with the MP algorithm to address the discrimination between two events. To position the new algorithm in the context of popular passive methods used, the proposed MP method has been compared with DWT-based technique. In the unusual event of only exact zero power mismatch, it is acknowledged that this passive MP method may not work alone, but that will be an extremely rare event. Even for minimal power mismatch ( $0.2 \%$ difference) the decomposition of signal subspace and noise subspace in the context of frequency estimation concept is being exploited as the estimation objective, which is also suitable for real-time implementation with the less computational burden. From the presented four different case studies, it was concluded that the proposed MP technique in comparison to the DWT-based technique is more robust and does not trigger any mal-operation in the event of grid harmonic pollution and other nonislanding switching transient cases where it can affect the grid voltage harmonics. However, detection time $(0.2 \mathrm{~s}$ in case of simulated and close to $0.1 \mathrm{~s}$ in real time) was large as compared with DWT-based technique, but then, again, it was much lower than the IEEE std. 1547 permissible limit of $2 \mathrm{~s}$.

\section{APPENDIX}

TABLE. I

Parameters of the Studied System

\begin{tabular}{|l|l|}
\hline \multicolumn{2}{|c|}{ Grid Parameters } \\
\hline Line-line voltage & $400 \mathrm{~V}$ \\
\hline Nominal frequency & $50 \mathrm{~Hz}$ \\
\hline \multicolumn{2}{|c|}{ Load parameters } \\
\hline Linear Resistive Load & Rated Power $=1.4 \mathrm{~kW}$ \\
\hline Load with QF=1 & $\begin{array}{l}\text { Rated Active Power }=1.4 \mathrm{~kW}, \\
\text { Rated Reactive Power }=2.8 \mathrm{kVar}\end{array}$ \\
\hline Load with QF=3 & $\begin{array}{l}\text { Rated Active Power }=1.4 \mathrm{~kW}, \\
\text { Rated Reactive Power }=4.2 \mathrm{kVar}\end{array}$ \\
\hline Load with QF=5 & $\begin{array}{l}\text { Rated Active Power }=1.4 \mathrm{~kW}, \\
\text { Rated Reactive Power=7 kVar }\end{array}$ \\
\hline $\begin{array}{l}\text { Non-Linear Load (Rectifier } \\
\text { Fed Resistive load) }\end{array}$ & $\begin{array}{l}\text { Rated Power }=0.685 \mathrm{~kW} \\
\text { Resistance }=22 \Omega\end{array}$ \\
\hline \multicolumn{2}{|c|}{ DG parameters } \\
\hline Rated Power & $1.4 \mathrm{~kW}$ \\
\hline AC Terminal Voltage & $230 \mathrm{~V}$ per phase \\
\hline DC Voltage & $400 \mathrm{~V}$ \\
\hline Filter parameter & $L=15 \mathrm{mH} /$ phase \\
& $C=10 \mu \mathrm{F} /$ phase \\
\hline Switching frequency & $2 \mathrm{kHz}$ \\
\hline Sampling time & $1 \mu \mathrm{S}$ \\
\hline & \\
\hline
\end{tabular}


TABLE II

POWER Mismatch and Estimated PaRAmeters

\begin{tabular}{|c|c|c|c|c|c|}
\hline$\overbrace{\tilde{\sigma}}^{\tilde{E}}$ & $\&$ & $\stackrel{\gamma}{\gamma}$ & 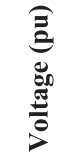 & 冚 & 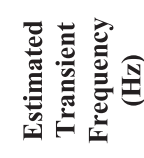 \\
\hline $\begin{array}{l}\text { Close } \\
\text { Power } \\
\text { Mismatch }\end{array}$ & $0.20 \%$ & $0 \%$ & 0.996 & 49.98 & 4.8 \\
\hline $\begin{array}{l}\text { Large } \\
\text { Power } \\
\text { Mismatch }\end{array}$ & $10.70 \%$ & $0 \%$ & 0.903 & 49.62 & 3.75 \\
\hline
\end{tabular}

\section{REFERENCES}

[1] C. Li, C. Cao, Y. Cao, Y. Kuang, L. Zeng, and B. Fang, "A review of islanding detection methods for microgrid," Renewable Sustain. Energy Rev., vol. 35, pp. 211-220, Jul. 2014.

[2] IEEE Standard For Interconnecting Distributed Resources With Electric Power Systems, IEEE Std 1547-2003, 2003.

[3] A. Khamis, H. Shareef, E. Bizkevelci, and T. Khatib, "A review of islanding detection techniques for renewable distributed generation systems," Renewable Sustain. Energy Rev., vol. 28, pp. 483-493, Dec. 2013.

[4] H. H. Zeineldin, E. F. El-Saadany, and M. M. A. Salama, "Impact of DG interface control on islanding detection and nondetection zones," IEEE Trans. Power Deliv., vol. 21, no. 3, pp. 1515-1523, Jul. 2006.

[5] A. M. I. Mohamad and Y. A.-R. I. Mohamed, "Assessment and performance comparison of positive feedback islanding detection methods in DC distribution systems," IEEE Trans. Power Electron., vol. 32, no. 8, pp. 6577-6594, Aug. 2017.

[6] D. Dong, B. Wen, P. Mattavelli, D. Boroyevich, and Y. Xue, "Modeling and design of islanding detection using phase-locked loops in three-phase gridinterface power converters," IEEE J. Emerg. Sel. Topics Power Electron., vol. 2 , no. 4, pp. 1032-1040, Dec. 2014.

[7] I. Mazhari, H. Jafarian, J. H. Enslin, S. Bhowmik, and B. Parkhideh, "Locking frequency band detection method for islanding protection of distribution generation," IEEE J. Emerg. Sel. Topics Power Electron., vol. 5, no. 3, pp. 1386-1395, Sep. 2017.

[8] Q. Sun, J. M. Guerrero, T. Jing, J. C. Vasquez, and R. Yang, "An islanding detection method by using frequency positive feedback based on FLL for single-phase microgrid," IEEE Trans. Smart Grid, vol. 8, no. 4, pp. 18211830, Jul. 2017

[9] X. Wang and W. Freitas, "Impact of positive-feedback anti-islanding methods on small-signal stability of inverter-based distributed generation," IEEE Trans. Energy Convers., vol. 23, no. 3, pp. 923-931, Sep. 2008.

[10] X. Wang, W. Freitas, V. Dinavahi, and W. Xu, "Investigation of positive feedback anti-islanding control for multiple inverter-based distributed generators," IEEE Trans. Power Syst., vol. 24, no. 2, pp. 785-795, May 2009.

[11] M. Hamzeh, N. Rashidirad, K. Sheshyekani, and E. Afjei, "A new islanding detection scheme for multiple inverter-based DG systems," IEEE Trans. Energy Convers., vol. 31, no. 3, pp. 1002-1011, Sep. 2016.

[12] M. Khodaparastan, H. Vahedi, F. Khazaeli, and H. Oraee, "A novel hybrid islanding detection method for inverter-based DGs using SFS and ROCOF," IEEE Trans. Power Deliv., vol. 32, no. 5, pp. 2162-2170, Oct. 2017.

[13] K. Jia, H. Wei, T. Bi, D. W. P. Thomas, and M. Sumner, "An islanding detection method for multi-DG systems based on high-frequency impedance estimation," IEEE Trans. Sustain. Energy, vol. 8, no. 1, pp. 74-83, Jan. 2017.

[14] R. A. Walling and N. W. Miller, "Distributed generation islandingimplications on power system dynamic performance," in IEEE Power Eng. Soc. Summer Meeting, 2002, pp. 92-96.

[15] N. Liu, C. Diduch, L. Chang, and J. Su, "A reference impedance-based passive islanding detection method for inverter-based distributed generation system," IEEE J. Emerg. Sel. Topics Power Electron., vol. 3, no. 4, pp. 1205-1217, Dec. 2015.
[16] W. Freitas, W. Xu, C. M. Affonso, and Z. Huang, "Comparative analysis between ROCOF and vector surge relays for distributed generation applications," IEEE Trans. Power Deliv., vol. 20, no. 2, pp. 1315-1324, Apr. 2005.

[17] B. Singam and L. Y. Hui, "Assessing SMS and PJD schemes of antiislanding with varying quality factor," in Proc IEEE Int. Power Energy Conf., 2006, pp. 196-201.

[18] A. Samui and S. R. Samantaray, "Assessment of ROCPAD relay for islanding detection in distributed generation," IEEE Trans. Smart Grid, vol. 2, no. 2, pp. 391-398, Jun. 2011.

[19] A. Emadi, H. Afrakhte, and J. Sadeh, "Fast active islanding detection method based on second harmonic drifting for inverter-based distributed generation," IET Gener. Transm. Distrib., vol. 10, no. 14, pp. 3470-3480, Nov. 2016.

[20] D. D. Reigosa, F. Briz, C. Blanco Charro, and J. M. Guerrero, "Passive islanding detection using inverter nonlinear effects," IEEE Trans. Power Electron., vol. 32, no. 11, pp. 8434-8445, Nov. 2017.

[21] S. Raza, H. Mokhlis, H. Arof, J. A. Laghari, and L. Wang, "Application of signal processing techniques for islanding detection of distributed generation in distribution network: A review," Energy Convers. Manage., vol. 96, pp. 613-624, May 2015.

[22] A. Pigazo, M. Liserre, R. A. Mastromauro, V. M. Moreno, and A. Dell'Aquila, "Wavelet-based islanding detection in grid-connected PV systems," IEEE Trans. Ind. Electron., vol. 56, no. 11, pp. 4445-4455, Nov. 2009.

[23] S. A. Saleh, A. S. Aljankawey, R. Meng, J. Meng, L. Chang, and C. P. Diduch, "Apparent power-based anti-islanding protection for distributed cogeneration systems," IEEE Trans. Ind. Appl., vol. 52, no. 1, pp. 83-98, Jan. 2016.

[24] M. Hanif, U. D. Dwivedi, M. Basu, and K. Gaughan, "Wavelet based islanding detection of DC-AC inverter interfaced DG systems," in Proc 45th Int. Univ. Power Eng. Conf., 2010, pp. 1-5.

[25] H. K. Karegar and B. Sobhani, "Wavelet transform method for islanding detection of wind turbines," Renewable Energy, vol. 38, no. 1, pp. 94-106, Feb. 2012.

[26] M. Hanif, M. Basu, and K. Gaughan, "Development of EN50438 compliant wavelet-based islanding detection technique for three-phase static distributed generation systems," IET Renewable Power Gener, vol. 6 , no. 4, p. 289-301, Jul. 2012.

[27] S. R. Samantaray, A. Samui, and B. C. Babu, "S-transform based cumulative sum detector (CUSUM) for islanding detection in distributed generations," in Proc Joint Int. Conf. Power Electron., Drives Energy Syst. Power India, 2010, pp. 1-6.

[28] A. H. Mohammadzadeh Niaki and S. Afsharnia, "A new passive islanding detection method and its performance evaluation for multi-DG systems," Elect. Power Syst. Res., vol. 110, pp. 180-187, May 2014.

[29] S. R. Mohanty, N. Kishor, P. K. Ray, and J. P. S. Catalao, "Islanding detection in a distributed generation based hybrid system using intelligent pattern recognition techniques," in Proc 3rd IEEE PES Innovative Smart Grid Technol. Eur., 2012, pp. 1-5.

[30] H. H. Zeineldin, T. Abdel-Galil, E. F. El-Saadany, and M. M. A. Salama "Islanding detection of grid connected distributed generators using TLSESPRIT," Elect. Power Syst. Res., vol. 77, no. 2, pp. 155-162, Feb. 2007.

[31] M. Bakhshi, R. Noroozian, and G. B. Gharehpetian, "Anti-islanding scheme for synchronous DG units based on Tufts-Kumaresan signal estimation method," IEEE Trans. Power Deliv., vol. 28, no. 4, pp. 2185-2193, Oct. 2013.

[32] G. Marchesan, M. R. Muraro, G. Cardoso, L. Mariotto, and A. P. de Morais, "Passive method for distributed-generation island detection based on oscillation frequency," IEEE Trans. Power Deliv., vol. 31, no. 1, pp. 138-146, Feb. 2016.

[33] A. Samui and S. R. Samantaray, "Wavelet singular entropy-based islanding detection in distributed generation," IEEE Trans. Power Deliv., vol. 28 no. 1, pp. 411-418, Jan. 2013.

[34] M. S. ElNozahy, E. F. El-Saadany, and M. M. A. Salama, "A robust wavelet-ANN based technique for islanding detection," in Proc IEEE Power Energy Soc. General Meeting, 2011, pp. 1-8.

[35] S. Alshareef, S. Talwar, and W. G. Morsi, "A new approach based on wavelet design and machine learning for islanding detection of distributed generation," IEEE Trans. Smart Grid, vol. 5, no. 4, pp. 1575-1583, Jul 2014.

[36] H. T. Do, X. Zhang, N. V. Nguyen, S. Li, and T. T.-T. Chu, "Passive islanding detection method using wavelet packet transform in grid connected photovoltaic systems," IEEE Trans. Power Electron., vol. 31, no. 10, pp. 6955-6967, Oct. 2016. 
[37] Y. Hua and T. K. Sarkar, "Matrix pencil method for estimating parameters of exponentially damped/undamped sinusoids in noise," IEEE Trans. Acoust., vol. 38, no. 5, pp. 814-824, May 1990.

[38] T. K. Sarkar and O. Pereira, "Using the matrix pencil method to estimate the parameters of a sum of complex exponentials," IEEE Antennas Propag. Mag., vol. 37, no. 1, pp. 48-55, Feb. 1995.

[39] J. E. Fernandez del Rio and T. K. Sarkar, "Comparison between the matrix pencil method and the fourier transform technique for high-resolution spectral estimation," Digit. Signal Process., vol. 6, no. 2, pp. 108-125, Apr. 1996.

[40] S. Agrawal, S. R. Mohanty, and V. Agarwal, "Harmonics and interharmonics estimation of wind power plant using sliding window matrix pencil," in Proc IECON-41st Annu. Conf. IEEE Ind. Electron. Soc., 2015 pp. 004984-004989.

[41] M. Bhuiyan, E. V. Malyarenko, M. A. Pantea, F. M. Seviaryn, and R. G. Maev, "Advantages and limitations of using matrix pencil method for the modal analysis of medical percussion signals," IEEE Trans. Biomed. Eng., vol. 60 , no. 2 , pp. 417-426, Feb. 2013.

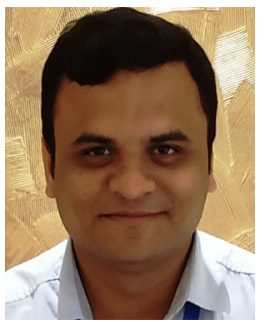

Sanjay Agrawal was born in Allahabad, India in 1987. He received the $M$. Tech degree in electrical engineering from NIT Hamirpur, India, in 2012, and the Ph.D. degree in electrical engineering from Motilal Nehru National Institute of Technology (MNNIT), Allahabad, India, in 2017.

$\mathrm{He}$ has worked with the School of Electrical and Electronic Engineering (SEEE), Dublin Institute of Technology, Ireland, for seven weeks in the year 2016 under the SFI-ISCA sponsorship scheme of Ireland Government. Since December 2017, he has been an Assistant Professor with the Electrical Engineering Department, Rajkiya Engineering College Ambedkar Nagar, Uttar Pradesh, India. His research interests include signal processing, artificial intelligence, renewable energy, and condition monitoring.

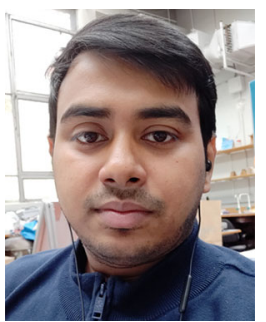

Sandipan Patra $\left(S^{\prime} 13\right)$ received the B.Tech degree in electronics and instrumentation engineering from West Bengal University of Technology, India, in 2011, and the master's degree in electrical engineering with specialization in power electronics and application specific integrated circuit (ASIC) design from Motilal Nehru National Institute of Technology (MNNIT), Allahabad, India, in 2013.

From 2013 to 2015, he was a Lecturer with IIIT Bhubaneswar, India. Currently, he is a Ph.D. Research Scholar with Dublin Institute of Technology, Dublin, Ireland. His research interests include low voltage power electronics, microgrid, power quality, and signal processing applications in power electronics.

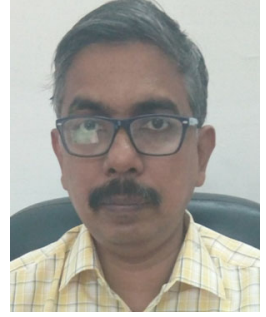

Soumya R. Mohanty (SM'12) received the Ph.D. degree in power system protection from the Department of Electrical Engineering, Indian Institute of Technology (IIT) Kharagpur, India, in 2007

He served more than ten years as Assistant Professor with the Department of Electrical Engineering, Motilal Nehru National Institute of Technology (MNNIT), Allahabad, India. He also worked as a Postdoctoral Fellow with University of Beira Interior, Portugal, and International Research collaboration as Short Research Exchange Program under Science Foundation (SFI-ISCA) with Dublin Institute of Technology, Ireland. $\mathrm{He}$ is presently working as Associate Professor with the Department of Electrical Engineering, Indian Institute of Technology (BHU), Varanasi, India. He has authored more than 35 papers with international journal of reputes and few papers in pipeline out of the research guidance of doctoral and master students and also ongoing projects with Department of Science and Technology, India. His research interests include digital signal processing applications in power system relaying and power quality, disturbance detection and classification, robust control scheme for load-frequency regulation in hybrid distributed generation based power system and microgrid, wide area monitoring and control in large scale power network.

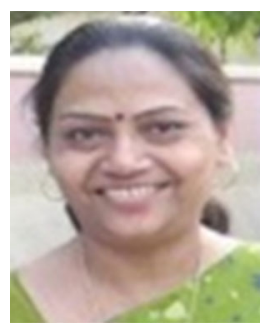

Vineeta Agarwal (SM'09) graduated in electrical engineering from Allahabad University, Allahabad, India, in 1980, and received the master's degree in power system from the same university, in 1984. She received the Ph.D. degree in power electronics while teaching at Motilal Nehru Regional Engineering College, Allahabad, India, in 1993.

She joined the Electrical Engineering Department at the Motilal Nehru Regional Engineering College, Allahabad, India, as a Lecturer in 1982 At present, she is a Professor with the Department of Electrical Engineering at the Motilal Nehru National Institute of Technology, Allahabad, India. She has authored a number of publications in journals and conferences in her field. Her research interests include single phase to three-phase conversion and ac drives.

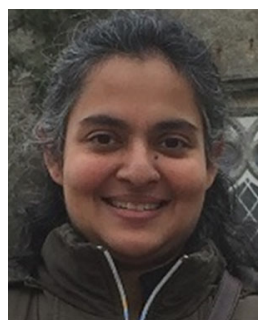

Malabika Basu (S'99-M'03) received the B.E. and M.E. degrees in electrical engineering from Bengal Engineering College, Shibpur, Kolkata, India, in 1995 and 1997, respectively, and the Ph.D. degree in electrical engineering from Indian Institute of Technology, Kanpur, Uttar Pradesh, India, in 2003

From 2001 to 2003, she was a Lecturer with Jadavpur University, Kolkata, West Bengal, India. From 2003 to 2006, she was Arnold F. Graves Postdoctoral Fellow with Dublin Institute of Technology, Dublin, Ireland, where she has been a Lecturer since 2006. She has authored or coauthored more than 90 technical publications in various international journals and conference proceedings. Her current research interests include grid integration of renewable energy sources, power quality conditioners, and power quality control and analysis, photovoltaics and wind energy conversion, HVdc systems, smart grid, and microgrids. 